\title{
Effects of Video-Guided Group vs. Solitary Meditation on Mindfulness and Social Connectivity: A Pilot Study
}

\author{
Adam W. Hanley ${ }^{1}\left[\right.$ D $\cdot$ Vincent Dehili $^{2} \cdot$ Deidre Krzanowski $^{3} \cdot$ Daniela Barou $^{4} \cdot$ Natalie Lecy $^{1} \cdot$ Eric L. Garland $^{1}$
}

Accepted: 9 June 2021 / Published online: 24 June 2021

(c) The Author(s), under exclusive licence to Springer Science+Business Media, LLC, part of Springer Nature 2021

\begin{abstract}
Interest in mindfulness meditation continues to grow as accumulating evidence suggests mindfulness training encourages more positive functioning. However, basic questions about the conditions best suited for realizing mindful states remain unanswered. Prominent among these is whether a group mindfulness practice setting is more effective for novice meditators than a solitary practice setting. Answering this question has assumed new urgency due to the imposition of physical distancing measures designed to stop the spread of COVID-19. In a time of limited social contact, is a simulated group practice setting better than practicing alone? This preliminary study investigated whether environmental setting impacted mindfulness practice experience by examining the effects of three simulated meditation practice environments (1. group practice, 2. nature practice, and 3. solitary practice) on state mindfulness and perceived social connectivity in a sample of novice meditators. Significant differences emerged across the three simulated practice settings. Findings suggest watching others meditate while meditating appears to most effectively induce a state of mindfulness and strengthen feelings of social connectivity. This study supports traditional beliefs about the benefits of group mindfulness practice. These findings also have implications for social workers struggling to stretch limited resources to address growing mental health demands, especially during times of heightened social isolation due to COVID-19. If a simulated group practice confers the same cognitive benefits as solitary practice while also conferring social benefits, simulated group instruction may be preferable for therapeutic and economic reasons.
\end{abstract}

Keywords Mindfulness $\cdot$ Meditation $\cdot$ Group practice $\cdot$ Nature $\cdot$ Solitary practice $\cdot$ Social connectivity $\cdot$ Social work . Mental health

\section{Introduction}

The ability to be mindful is thought to be a natural human capacity (Brown \& Ryan, 2003), which can be intentionally developed through sustained practice (Carmody \& Baer, 2008). Kabat-Zinn (1994) defines mindfulness as "paying attention in a particular way: on purpose, in the present moment, and non-judgmentally" (p. 4). However, in the literature, the word "mindfulness" has been used in multiple

Adam W. Hanley

adam.hanley@utah.edu

1 College of Social Work, University of Utah, Salt Lake City, USA

2 North Carolina State University, Raleigh, USA

3 Bethesda Hospital East, Boynton Beach, USA

4 LifeStance Health, Bellevue, USA ways, denoting a momentary state, an enduring trait, and a style of contemplative practice. The momentary state of mindfulness realized during a mindfulness practice will be the primary focus of the present study. Evidence suggests mindfulness practices, such as mindfulness meditation and yoga, can improve the mental and physical functioning of healthy adults (Eberth \& Sedlmeier, 2012; Khoury et al., 2015), and mindfulness-based interventions are effective treatment tools for clinical concerns ranging from chronic pain (Garland et al., 2014, 2019), to depression (Harnett et al., 2010; Ma \& Teasdale, 2004; Teasdale et al., 2000) and disordered eating (Dalen et al., 2010; Kristeller \& Hallett, 1999). As evidence supporting the benefits of mindfulness accumulates and become more widely disseminated, it is not surprising that the number of meditating American adults has grown from 4\% in 2012 to $15 \%$ in 2017 (Clarke et al., 2018). With this surge in new mindfulness practitioners, a better understanding of the social and environmental 
conditions that would best support someone in beginning and maintaining a mindfulness practice is needed.

Although empirical evidence supports the efficacy of inperson mindfulness-based interventions, it remains unclear how different mindfulness practice conditions (e.g., solitary vs. group, formal vs. informal, in-person vs. virtual) influence meditative experiences, particularly for novice meditators. In fact, the social and environmental conditions potentially impacting the cognitive state of mindfulness have largely been neglected in mindfulness research. If novice practitioners fail to experience the immediate benefits of mindfulness practice, they are less likely to maintain their practice, subsequently losing out on potential health benefits. Theory and anecdote suggest group mindfulness practice is more effective for novice meditators than solitary practice (e.g., Gunaratana, 1992; Nhat Hanh, 1998). Traditional mindfulness training methods promote the idea of Sangha, a traditional Buddhist concept denoting an active community of Buddhist practitioners. Thich Nhat Hanh (1998), an influential Buddhist monk and author, asserts that "practicing with a Sangha is essential. Even if we have a deep appreciation for the practice, it can be difficult to continue without the support of friends." (p. 164). A substantial portion of Hahn's (1998) The Heart of Buddha's Teaching emphasizes the importance of Sangha. Reciprocally, engagement with mindfulness practice has been found to promote the experience of social support and connection (Pruitt \& McCollum, 2010; Rothaupt \& Morgan, 2007). As such, group mindfulness practice may work synergistically to enhance both the state of mindfulness and the sense of social connection (i.e., belonging to a social relationship or social network; Lee \& Robbins, 1995). Moreover, group practice is commonly believed to encourage continuity of practice due to the experience of accountability and an established, regular practice schedule (Gunaratana, 1992). Lauricella (2013) echoes and expands on these assertions, offering "a sense of accountability, supervision from the instructor, or feelings of commitment to the group" (p. 2) as hypothetical benefits of group practice. Thus, preliminary qualitative evidence coupled with tradition and anecdote suggest that group practice is best for novice practitioners. However, in contrast, survey data revealed that American adults reported preferring an individual practice format to a group format (Wahbeh et al., 2014). Surprisingly, internet based asynchronous training was the most preferred format in this sample (Wahbeh et al., 2014).

To date, Lauricella's (2013) exploration of group vs. solitary practice preference is the only experimental investigation addressing perceived differences in beginning meditators' experience of meditation across environmental settings. Forty undergraduate students in a communication class received course credit for attending a mindfulness introduction session and listening to a recorded version of the mindfulness practice on their own the week following the classroom practice. While both practices were reported to be calming, with positive experiences reported by $96 \%$ of the students, the group session was experienced more positively by a greater number of respondents $(58 \%)$. Positive ratings of the group practice were attributed to feelings of personal connection with the instructor and classmates during the group practice session. Comparatively, $26 \%$ of students rated the solitary practice more positively, indicating that practicing alone allowed them to avoid any potential embarrassment that may have occurred during the group mediation setting (e.g., falling asleep). Of the remaining participants, $10 \%$ reported no practice environment preference (Lauricella, 2013). Thus, in-person, group mindfulness practice was preferred by the majority of novice practitioners, principally due to the feelings of social connection that arose in the group setting. However, whether a simulated group practice setting (e.g., online group practice video, virtual reality meditation hall) results in similar practice effects and feelings of social connection has not been examined, and the lockdown which has occurred in many countries as a response to the Coronavirus Disease pandemic (COVID-19), has made further exploration of simulated practice settings imperative.

Determining the conditions most conducive for mindfulness training is a pressing concern as the physical distancing measures designed to stop COVID-19's spread have severely limited access to in-person mindfulness trainings and therapies (Chen et al., 2020; Reay et al., 2020). Behavioral interventions that were previously delivered in-person are either discontinued or moving online, en masse. As a result, many mindfulness practitioners and aspirants are being forced to pursue solitary practice or find a virtual practice group. Simultaneously, many Americans are in even greater need of the equanimity and sense of connectedness often cultivated during mindfulness practice (Desbordes et al., 2014), as COVID-19 continues to increase feelings of social isolation, depression, and anxiety (Panchal et al., 2020). Indeed, rising suicide rates are deeply concerning as social workers and related mental health providers are less accessible due to increasing demands for their services (Sher, 2020) and COVID-19 related limitations such as office closures. These mounting pressures herald a desperate need for innovative service delivery; and, mindfulness practices offer a practical conduit for emotional stabilization and growth. Compounding COVID-19 related service barriers are more traditional obstacles to mental health care access, including transportation, childcare, distance, and timing (Cunningham, 2009; Moskalenko et al., 2020), which disproportionately impact historically marginalized communities. Social workers are explicitly called to address the systemic disparities preventing disenfranchised populations from receiving services (NASW, 2017). Developing effective interventions, accessible to vast audiences ensures greater access to needed mental 
health care for all and web-based services may be able to reach a wider audience by circumventing many of the traditional and more recent barriers to service access.

Online mindfulness-based interventions have already shown promise in both general and clinical populations (Cavanagh et al., 2013; Cillessen et al., 2018; Glück \& Maercker, 2011; Kemper \& Yun, 2015; Niles et al., 2013), with perceived benefits such as added convenience and flexibility as well as the ability to fill gaps in current healthcare practices (El Morr et al., 2020). This promise is of immense value as COVID-19 continues to tax the health care system and reshape the social landscape. Not only do online mindfulness-based interventions have the potential to provide access to the growing numbers of people interested in practicing mindfulness for personal or health reasons, they may also provide a much-needed sense of community and social connection during periods of isolation, whether forced or otherwise. Indeed, online or remote mindfulness-based interventions may be able to reach people with limited opportunity for in-person mindfulness training (Moskalenko et al., 2020; Saurman et al., 2015). Although not all Americans have the resources for at-home broadband, $81 \%$ of American adults own smartphones and lower-income Americans increasingly use smartphones in replacement of purchasing broadband internet (Pew Research Center, 2021). Thus, lower-income households have better access than ever before to web-based and remote services (Pew Research Center, 2021) making them a relevant platform for mental health service delivery.

\section{Introduction to the Present Study}

Whether group practice promotes greater state mindfulness and social cohesion remains largely unknown. With only one experimental study addressing practice environment preference (Lauricella, 2013), continued examination of the most effective practice setting for novice practitioners is neededparticularly with respect to online environments. To this end, the primary aim of this study was to examine the effect of an online, video-guided meditation on state mindfulness and social connection in three practice settings: (1) the group practice setting, (2) the nature practice setting, or (3) the solitary practice setting. It was hypothesized that participants randomly assigned to view the simulated group practice setting would report greater state mindfulness and social connection compared to those participants in the simulated nature practice setting or the solitary practice setting.

\section{Method}

\section{Participants}

Participants $(n=52)$ were recruited from a large Southeastern university's voluntary College of Education Research
Subject Pool. Participants were primarily female $(90 \%)$ and Caucasian $(65 \%)$ or Latino $(19 \%)$, with a mean age of $20(S D=1.93)$. The majority of respondents were 4th(31\%) or 3rd- $(29 \%)$ year students, with 1 st- and 2 nd-year students accounting for $20 \%$ of respondents, respectively. Protestant/Evangelical Christian (42\%) and Catholic (25\%) were the most commonly reported religious affiliations, while $25 \%$ of respondents reported no affiliation.

\section{Procedures}

The study was approved by the Institutional Review Board at a large Southeastern university. All surveys and the video-guided mindfulness practice were completed during a single experimental session, lasting approximately 26 min. Experimental sessions were conducted individually and all study procedures occurred in a private room. Following consent, participants completed the measures of dispositional mindfulness and state affect to ensure group equivalency and that trait characteristics would not bias effects on state mindfulness and social connection. Then, participants were randomly assigned to one of three videoguided mindfulness practice conditions: (1) the group practice setting, in which they watched a video of a group meditation session while listening to the guided meditation, (2) the nature practice setting, in which they watched a nature scene while listening to the guided meditation, or (3) the solitary practice setting, in which they watched a blank screen while listening to the guided meditation.

Still photographs of the group meditation and nature scene videos are provided in Fig. 1. Videos were used to standardize participants' experiences and reduce social confounds, such as existing relationships, group conflicts, or friendly interactions. Furthermore, evidence supports the use of video to model a diversity of health behaviors (Tuong et al., 2014), such as exercise (Dyson et al., 2010; Morie \& Chance, 2011) HIV testing (Blas et al., 2010; Calderon et al., 2007), and sunscreen application (Armstrong et al., 2011). The nature scene condition was included to expand the solitary mindfulness practice setting options and to control for any impact the visual stimulation of video watching may create while meditating. During the mindfulness practice, participants were seated directly in front of a computer monitor, provided noise canceling headphones to minimize external distractions, and instructed to let their eyes rest gently on the computer monitor. A pre-recorded body scan meditation, adapted from Kabat-Zinn (1990), was used to promote the state of mindfulness. The body scan instructed participants to direct their attention to locations in their body, guiding them sequentially from the top of their head to the bottom of their feet. Participants were encouraged to return 


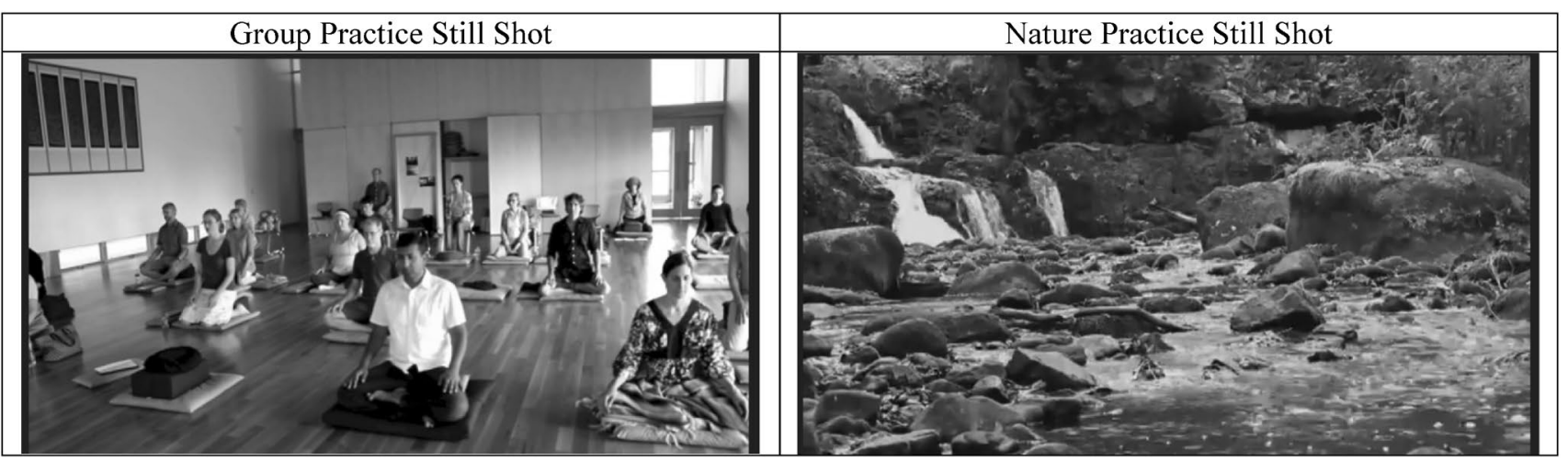

Fig. 1 Still shots of group and nature practice videos

their attention to their body whenever they became aware that their mind had wandered. Each virtual guided meditation lasted $8 \mathrm{~min}$. Following the mindfulness practice, participants completed measures of state mindfulness and social connection, enabling the research team to assess any between group differences.

\section{Measures}

\section{Dispositional Mindfulness}

The Five Facet Mindfulness Questionnaire (FFMQ; Baer et al., 2006) is a well validated measure of dispositional mindfulness consisting of 39 items rated on a 5-point Likert Scale. Dispositional mindfulness is conceptualized as "trait" mindfulness-a stable characteristic inherent as a human capacity (Tomlinson et al., 2018). Only the FFMQ total score was used in this study to ensure group equivalency at pre-testing $(\alpha=.81)$.

\section{State Mindfulness}

The Toronto Mindfulness Scale (TMS; Lau et al., 2006) is a well validated measure of state mindfulness consisting of 13 items rated on a 5-point Likert Scale. State mindfulness is a momentary condition which can be enhanced by mindfulness-based practices (Tomlinson et al., 2018). The TMS has two unique dimensions, curiosity (e.g., "I was curious about my reactions to things"; $\alpha=.87$ ) and decentering (e.g., "I was aware of my thoughts and feelings without over-identifying with them"; $\alpha=.81$ ). The summed rating across all the scores represents the total state mindfulness score, with higher scores reflecting greater state mindfulness $(\alpha=.89)$.

\section{Social Connectedness}

The Social Connectedness Scale (SCS; Lee \& Robbins, 1995) is an 8-item measure scored on 6-point Likert Scale assessing interpersonal closeness in the social realm (Dvorakova et al., 2017). The SCS is a uni-dimensional assessment, with higher summed rating reflecting an enhanced sense of social connection $(\alpha=.93)$. Sample SCS items include: "I feel disconnected from the world around me", and "Even around people I know, I don't feel that I really belong".

\section{State Affect}

The Positive Affect and Negative Affect Scale (PANAS; Watson et al., 1988) is a well validated measure of state affect consisting of 20 adjectives that are rated on a 6-point Likert Scale. It is one of the most widely used measures assessing momentary emotion or mood (Tran, 2013). A total negative affect score is derived by taking the mean rating across all the negatively valenced adjectives (distressed, upset, guilty, scared, hostile, irritable, ashamed, nervous, jittery, and afraid; $\alpha=.78$ ) whereas a total positive affect score is derived by taking the mean rating across all the positively valenced adjectives (interested, excited, strong, enthusiastic, proud, alert, inspired, determined, attentive, and active; $\alpha=.87$ ).

\section{Statistical Analysis}

Multivariate analysis of variance (MANOVA) was used to establish between group equivalency at pre-testing in dispositional mindfulness and state affect as well as determine between group differences at post-testing in state mindfulness and social connectedness. Power analysis using an effect size estimate $\left(\eta^{2}=.20\right)$ reported in previous studies of brief mindfulness inductions (e.g., Erisman \& Roemer, 2010; Zeidan et al., 2010) indicated a total sample size of 48 was needed to adequately power the present study. 


\section{Results}

\section{State Mindfulness and Social Connection}

No significant between group differences were observed at pre-testing in dispositional mindfulness or state affect $\left(F_{6,96}=1.61, p=.15\right)$. See Table 1 for details. Significant between group differences in state mindfulness and social connection were observed at post-testing $\left(F_{6,96}=1.61\right.$, $p=.001$, partial $\eta^{2}=.21$ ).

State mindfulness differed by group $\left(F_{2,49}=3.38\right.$, $p=.042$, partial $\eta^{2}=.12$ ) and a least square difference (LSD) post hoc analysis was used to test predetermined contrasts in state mindfulness. Participants in the group practice condition reported significantly higher levels of state mindfulness than participants in the nature practice condition ( $\bar{x}$ difference $=7.75, p=.015)$. The difference between the solitary and nature practice conditions was non-significant $(\bar{x}$ difference $=5.47, p=.10$ ) as was the difference between the group and solitary practice conditions ( $\bar{x}$ difference $=2.28, p=.77$ ). These group differences appeared to be primarily a function of significant between group differences in the decentering domain of state mindfulness $\left(F_{2,49}=6.55, p=.003\right.$, partial $\eta^{2}$ $=.21$ ). Similar to the total score, LSD post hoc analysis indicated significantly higher decentering scores in the group practice condition when compared with the nature practice condition ( $\bar{x}$ difference $=5.96, p=.001)$, but participants in the solitary practice condition also reported significantly higher decentering scores than participants in the nature practice condition $(\bar{x}$ difference $=3.55, p=.047)$. Again, no significant difference between the group practice and solitary practice conditions was observed ( $\bar{x}$ difference $=2.41$, $p=.18)$. The curiosity domain of state mindfulness did not differ by group $\left(F_{2,49}=0.77, p=.47\right)$.

Social connection also differed by group $\left(F_{2,49}=4.12\right.$, $p=.022$, partial $\eta^{2}=.14$ ). LSD post hoc analysis indicated that the group practice condition reported significantly higher levels of social connection when compared with the solitary practice condition ( $\bar{x}$ difference $=6.94, p=.006$ ). The difference between the group and nature practice conditions was non-significant ( $\bar{x}$ difference $=2.70, p=.24$ ) as was the difference between the nature and solitary practice conditions ( $\bar{x}$ difference $=4.25, p=.08$ ).

\section{Discussion}

While traditional knowledge suggests that group mindfulness practice is more effective for novice meditators than solitary practice (e.g., Gunaratana, 1992; Nhat Hanh, 1998), almost no empirical studies have tested this claim. Additionally, no known study has examined the added benefit of an online, video-guided group mindfulness practice, a domain of pressing interest given dramatic increases in telehealth and asynchronous intervention models resulting from the COVID-19 pandemic. This study filled a critical gap in mindfulness literature by exploring which of three videoguided meditation conditions (i.e., group practice, nature practice, or solitary practice) most effectively promoted state mindfulness and social connectedness in a group of novice meditators. Results indicated the video guided group meditation and solitary, blank screen conditions were the most effective for inducing the state of mindfulness. However, an important difference was observed between these two conditions with respect to social connectivity. The video-guided group meditation resulted in significantly greater reports of social connectedness. These findings appear congruent with emerging evidence suggesting most novice practitioner prefer in-person group practice to solitary practice and find group practice to encourage feelings of social connectivity (Lauricella, 2013).

More generally, evidence that a video-guided group meditation practice increases state mindfulness and social connectivity is resonant with traditional Buddhist thought concerning the benefits of group training for beginning meditators (Gunaratana, 1992; Hanh, 1998). This study's findings provide empirical evidence that a brief mindfulness
Table 1 Means, standard deviations, and between group comparisons for the primary variables of interest

\begin{tabular}{lllllll}
\hline Variable & $\begin{array}{l}\text { Group }(N=18) \\
\text { Mean }(S D)\end{array}$ & $\begin{array}{l}\text { Nature }(N=19) \\
\text { Mean }(S D)\end{array}$ & $\begin{array}{l}\text { Solitary }(N=15) \\
\text { Mean }(S D)\end{array}$ & $F$ & $p$ & $\eta^{2}$ \\
\hline Pre-testing & & & & & \\
Dispositional mindfulness & $110.61(13.93)$ & $113.79(12.01)$ & $117.07(12.79)$ & 1.02 & .37 & - \\
Positive affect & $30.56(7.68)$ & $27.16(6.94)$ & $25.27(7.02)$ & 2.31 & .11 & - \\
Negative affect & $12.50(2.26)$ & $14.79(4.67)$ & $13.73(5.46)$ & 1.33 & .28 & - \\
Post-testing & & & & & & \\
State mindfulness & $43.28(7.61)$ & $35.53(10.84)$ & $41.00(9.06)$ & 3.38 & .04 & .12 \\
Curiosity & $20.00(4.73)$ & $18.21(5.75)$ & $20.13(4.93)$ & 0.77 & .47 & .03 \\
Decentering & $23.28(4.08)$ & $17.32(5.91)$ & $20.87(4.88)$ & 6.55 & .003 & .21 \\
Social connectedness & $42.28(6.25)$ & $39.58(6.41)$ & $35.33(8.27)$ & 4.12 & .02 & .14 \\
\hline
\end{tabular}


meditation done in the presence of a simulated meditation group is likely to increase feelings of connection with fellow meditators. Thus, sangha may begin developing in the first minutes of mediation; and it may be these feelings of connection help sustain practice. Whether connectivity (i.e., sangha) moderates continued meditation practice involvement is an empirical question that should be pursued by future research. Western psychological thought may also help explain the social influence of the simulated group meditation practice observed in this study. Specifically, social learning theory (Bandura, 1977), which emphasizes observational learning, would suggest that group practice would likely promote mindfulness beyond solitary practice. Indeed, the virtual meditators in the simulated group meditation condition likely served as meditation "models" for the novice meditators.

Beyond the observed experiential benefits, findings from this study may also have implementation implications for social workers struggling to stretch limited resources to address growing mental health demands in a shifting healthcare landscape. If video-guided group mindfulness practice confers the same psychological benefits as solitary practice while also conferring social benefits, video-guided group instruction may be preferable when in-person instruction is unavailable. Moreover, given the social benefit of group practice in this study, video-guided group mindfulness practices may be particularly valuable for isolated populations (e.g., older adults in assisted living facilities) and for populations with limited access to mental health services (e.g., low SES, rural). While not all clients will be interested in participating in group platforms, video-guided group practices serve as additional resources for those seeking services.

Mindfulness practices aid in shifting awareness to the present moment, promoting non-judgmental acceptance of self, and enhancing equanimity (Desbordes et al., 2014; Shoham et al., 2018). This ability to step outside of life's worries or feelings of chaos enhance meta-cognitive skills (Geschwind et al., 2011). Arguably, these tools could be universally beneficial for those we serve, especially for those currently suffering from increased isolation due to COVID-19. The accessibility and adaptability of mindfulness practices make them a valuable resource for integration into to both clinical and non-clinical social work settings. Social work practitioners with training in mindfulness can adapt practices to incorporate into their daily work with clients. There are many avenues for incorporating mindfulness into social work practice. Social work providers could begin sessions with a short mindfulness practice to promote grounding, conduct guided meditations, or offer mindfulness resources for consumers to access at home. Considering the benefits of group mindfulness practice and the need for greater access to mental health care; social workers could create their own virtual mindfulness groups tailored toward populations they serve or refer to groups already in existence (Integrative Mindfulness, 2021; Mindful Leader, 2021).

With the accessibility of online video hosting platforms, such as YouTube (Madathil et al., 2014) or Vimoe (Chilukuri \& Raju, 2015), creating a video-guided mindfulness practice is as easy as uploading a recording and sharing a web address.

Additionally, findings from this study have implications for the growing number of online mindfulness training platforms, such as Calm (2020) and Headspace (2020). These online platforms may want to consider offering online users the option of viewing a group meditation video while listening to their audio-guided mindfulness practices to support feelings of social connection. More generally, results from this study highlight the need for continued research on mindfulness practice conditions. If something as trivial as watching a certain type of video while listening to a mindfulness practice can influence practice outcomes, in what other ways can we shape mindfulness practice environments to optimize practice experiences?

Despite these important clinical implications and future research directions, limitations in this study should be noted. First, the video-guided mindfulness practices could not capture the full, lived experience of meditating with a group or meditating in nature. Future studies with greater ecological validity that examine the effects of meditating in group and nature settings in vivo are needed to verify these initial findings. Future studies may also wish to compare in-person group practice to interactive video-guided group practice (e.g., Zoom Meeting, Google Hangout) or even virtual reality group practice, and perhaps explore differences in state mindfulness and social cohesion over multiple mindfulness training sessions to examine if the effects observed in this study continue over time. Second, while both the state mindfulness (e.g., Erisman \& Roemer, 2010; Johnson et al., 2015; Ortner et al., 2007) and social connectedness (Kaplan et al., 2014; Mellor et al., 2008; Neff \& Germer, 2013) scales are regularly used as outcome measures, it may be the study groups differed in their levels of state mindfulness and social connection at baseline. Although we did not find any significant between group differences in dispositional mindfulness or affective state at baseline in this study, future studies may wish to measure both state mindfulness and social connections at baseline to verify group equivalency. Relatedly, using a mixed methods approach in a future study would allow for a more complete understanding of participant experiences. Third, the small sample size leaves the results tentative, but valuable given the absence of empirical data on role the online/social environment plays during mindfulness practice. Increasing the sample size in future studies would likely provide a clearer picture of the findings with respect to state mindfulness and social connectivity. Finally, that the sample was primarily young, Caucasian females 
limits the generalizability of these findings. Nevertheless, each of these limitations could be reasonably addressed by future research.

\section{Conclusion}

Expanding services offered through online video-guided groups would provide greater accessibility to those who may not traditionally have access mental health resources due to lack of transportation, childcare needs, rurality, or being housebound. Further, people of color, males, and veterans may be deterred from physically accessing mental health services due to societal stigma (Williston et al., 2019). Offering mindfulness interventions through an online platform could alleviate barriers traditionally experienced by populations needing care. Increasing access to mental health care speaks to the core values inherent in social work ethics by meeting "the basic human needs of all people with particular attention to the needs and empowerment of people who are vulnerable, oppressed, and living in poverty" (NASW, 2017).

Overall this study's findings provide important preliminary insights into the varied effects of setting and circumstance in influencing experiences of mindfulness meditation. These results shed light on the utility of group mindfulness practices for novice practitioners. Further, implications from this study are particularly relevant due to the need for innovative approaches to address the mental health needs of a growing population effected by the COVID-19 pandemic. This research is also germane to social workers who are inherently called to address systemic disparities preventing disenfranchised populations from receiving services. Online services are able to reach a wider audience at a time when many mental health professionals are beyond their capacity. Developing effective interventions, accessible to vast audiences ensures greater access to needed mental health care for all.

\section{References}

Armstrong, A. W., Idriss, N. Z., \& Kim, R. H. (2011). Effects of videobased, online education on behavioral and knowledge outcomes in sunscreen use: A randomized controlled trial. Patient Education and Counseling, 83(2), 273-277.

Baer, R. A., Smith, G. T., Hopkins, J., Krietemeyer, J., \& Toney, L. (2006). Using self-report assessment methods to explore facets of mindfulness. Assessment, 13(1), 27-45.

Bandura, A. (1977). Social learning theory. Prentice-Hall.

Blas, M. M., Alva, I. E., Carcamo, C. P., Cabello, R., Goodreau, S. M., Kimball, A. M., \& Kurth, A. E. (2010). Effect of an online videobased intervention to increase HIV testing in men who have sex with men in Peru. PLoS ONE, 5(5), e10448.
Brown, K. W., \& Ryan, R. M. (2003). The benefits of being present: Mindfulness and its role in psychological well-being. Journal of Personality and Social Psychology, 84(4), 822-848.

Calderon, Y., Haughey, M., Leider, J., Bijur, P. E., Gennis, P., \& Bauman, L. J. (2007). Increasing willingness to be tested for human immunodeficiency virus in the emergency department during offhour tours: A randomized trial. Sexually Transmitted Diseases, 34(12), 1025-1029.

Calm. (2020). Find your calm. Retrieved from https://www.calm.com

Carmody, J., \& Baer, R. A. (2008). Relationships between mindfulness practice and levels of mindfulness, medical and psychological symptoms and well-being in a mindfulness-based stress reduction program. Journal of Behavioral Medicine, 31, 23-33.

Cavanagh, K., Strauss, C., Cicconi, F., Griffiths, N., Wyper, A., \& Jones, F. (2013). A randomized controlled trial of a brief online mindfulness-based intervention. Behaviour Research and Therapy, 51(9), 573-578. https://doi.org/10.1016/j.brat.2013.06.003

Chen, J. A., Chung, W. J., Young, S. K., Tuttle, M. C., Collins, M. B., Darghouth, S. L., Longley, R., Levy, R., Razafsha, M., Kerner, J. C., Wozniak, J., \& Huffman, J. (2020). COVID-19 and telepsychiatry: Early outpatient experiences and implications for the future. General Hospital Psychiatry, 66, 89-95. https://doi.org/10.1016/j. genhosppsych.2020.07.002

Chilukuri, K. C., Raju, K. V. L. (2015) PPP: A paradigm for online education in engineering colleges. In R. Natarajan (Ed.), Proceedings of the international conference on transformations in engineering education. Springer. https://doi.org/10.1007/978-81322-1931-6 37

Cillessen, L., Schellekens, M. P. J., Van de Ven, M. O. M., Donders, A. R. T., Compen, F. R., Bisseling, E. M., Van der Lee, M., \& Speckens, A. E. M. (2018). Consolidation and prediction of the long-term treatment effect of group and online mindfulness-based cognitive therapy for distressed cancer patients. Acta Oncologica, 57(10), 1293-1302. https://doi.org/10.1080/0284186x.2018. 1479071

Clarke, T. C., Barnes, P.M., Black, L. I., Stussman, B. J., Nahin, R. L. (2018) Use of yoga, meditation, and chiropractors among U.S. adults aged 18 and over. NCHS Data Brief, no 325. Hyattsville, MD: National Center for Health Statistics.

Cunningham, P. J. (2009). Beyond parity: Primary care physicians' perspectives on access to mental health care. Health Affairs, 28, 490-501. https://doi.org/10.1377/hlthaff.28.3.w490

Dalen, J., Smith, B. W., Shelley, B. M., Sloan, A. L., Leahigh, L., \& Begay, D. (2010). Mindful eating and living (MEAL): Eating behaviors and psychological outcomes associated with a mindfulness-based intervention for people with obesity. Complementary Therapies in Medicine, 18, 260-264.

Desbordes, G., Gard, T., Hoge, E. A., Hölzel, B. K., Kerr, C., Lazar, S. W., Olendzki, A., \& Vago, D. R. (2014). Moving beyond mindfulness: Defining equanimity as an outcome measure in meditation and contemplative research. Mindfulness. https://doi.org/10.1007/ s12671-013-0269-8

Dvorakova, K., Kishida, M., Li, J., Elavsky, S., Broderick, P., Agrusti, M., \& Greenberg, M. T. (2017). Promoting healthy transition to college through mindfulness training with first-year college students: Pilot randomized controlled trial. Journal of American College Health, 65, 259-267.

Dyson, P. A., Beatty, S., \& Matthews, D. R. (2010). An assessment of lifestyle video education for people newly diagnosed with type 2 diabetes. Journal of Human Nutrition and Dietetics, 23(4), 353-359.

Eberth, J., \& Sedlmeier, P. (2012). The effects of mindfulness meditation: A meta-analysis. Mindfulness. https://doi.org/10.1007/ s12671-012-0101-x 
El Morr, C., Maule, C., Ashfaq, I., Ritvo, P., \& Ahmad, F. (2020). Design of a Mindfulness Virtual Community: A focus-group analysis. Health Informatics Journal, 26(3), 1560-1576.

Erisman, S. M., \& Roemer, L. (2010). A preliminary investigation of the effects of experimentally induced mindfulness on emotional responding to film clips. Emotion, 10(1), 72.

Garland, E. L., Manusov, E. G., Froeliger, B., Kelly, A., Williams, J. M., \& Howard, M. O. (2014). Mindfulness-oriented recovery enhancement for chronic pain and prescription opioid misuse: results from an early-stage randomized controlled trial. Journal of Consulting and Clinical Psychology, 82(3), 448-459.

Garland, E. L., Hanley, A. W., Riquino, M. R., Reese, S. E., Baker, A. K., Salas, K., Yack, B. P., Bedford, C. E., Bryan, M. A., Atchley, R., Nakamura, Y., Froeliger, B., \& Howard, M. O. (2019). Mindfulness-oriented recovery enhancement reduces opioid misuse risk via analgesic and positive psychological mechanisms: A randomized controlled trial. Journal of Consulting and Clinical Psychology, 87(10), 927-940.

Geschwind, N., Peeters, F., Drukker, M., van Os, J., \& Wichers, M. (2011). Mindfulness training increases momentary positive emotions and reward experience in adults vulnerable to depression: A randomized controlled trial. Journal of Consulting and Clinical Psychology, 79(5), 618-628.

Glück, T. M., \& Maercker, A. (2011). A randomized controlled pilot study of a brief web-based mindfulness training. BMC Psychiatry, 11(1), 175. https://doi.org/10.1186/1471-244X-11-175

Gunarantana, H. (1992). Mindfulness in plain English. Wisdom Publications.

Harnett, P. H., Whittingham, K., Puhakka, E., Hodges, J., Spry, C., $\&$ Dob, R. (2010). The short-term impact of a brief group-based mindfulness therapy program on depression and life satisfaction. Mindfulness, 1(3), 183-188.

Headspace. (2020). Be kind to your mind. Retrieved from https://www. headspace.com

Integrative Mindfulness. (2021). Ready to commit to your mindfulness meditation practice? Retrieved from https://www.integrativemind fulness.net/online-meditation-group

Johnson, S., Gur, R. M., David, Z., \& Currier, E. (2015). One-session mindfulness meditation: A randomized controlled study of effects on cognition and mood. Mindfulness, 6(1), 88-98.

Kabat-Zinn, J. (1990). Full catastrophe living: Using the wisdom of your mind and body to face stress, pain, and illness. Delacorte.

Kabat-Zinn, J. (1994). Wherever you go, there you are: Mindfulness meditation in everyday life. Hyperion.

Kaplan, S., Bradley-Geist, J. C., Ahmad, A., Anderson, A., Hargrove, A. K., \& Lindsey, A. (2014). A test of two positive psychology interventions to increase employee well-being. Journal of Business and Psychology, 29, 367-380.

Kemper, K. J., \& Yun, J. (2015). Group online mindfulness training: Proof of concept. Journal of Evidence-Based Complementary \& Alternative Medicine, 20(1), 73-75. https://doi.org/10.1177/21565 87214553306

Khoury, B., Sharma, M., Rush, S. E., \& Fournier, C. (2015). Mindfulness-based stress reduction for healthy individuals: A metaanalysis. Journal of Psychosomatic Research, 78(6), 519-528.

Kristeller, J. L., \& Hallett, C. B. (1999). An exploratory study of a meditation-based intervention for binge eating disorder. Journal of Health Psychology, 4, 357-363.

Lau, M. A., Bishop, S. R., Segal, Z. V., Buis, T., Anderson, N. D., Carlson, L., et al. (2006). The Toronto Mindfulness Scale: Development and validation. Journal of Clinical Psychology, 62, 1445-1467.

Lauricella, S. (2013). Mindfulness meditation with undergraduates in face-to-face and digital practice: A formative analysis. Mindfulness, 5(6), 682-688.
Lee, R. M., \& Robbins, S. B. (1995). Measuring belongingness: The Social Connectedness and the Social Assurance scales. Journal of Counseling Psychology, 42, 232.

Madathil, K. C., Rivera-Rodriguez, A. J., \& Greenstein, J. S. (2014). Healthcare information on YouTube: A systematic review. Health Informatics Journal, 21, 173-194.

Mellor, D., Firth, L., \& Moore, K. (2008). Can the internet improve the well-being of the elderly? Ageing International, 32, 25-42.

Mindful Leader. (2021). Free online group meditation: Meditate together. Retrieved from https://www.mindfulleader.org/medit ate-together

Morie, J. F., \& Chance, E. (2011). Extending the reach of health care for obesity and diabetes using virtual worlds. Journal of Diabetes Science and Technology, 5, 272-276. https://doi.org/10.1177/ 193229681100500211

Moskalenko, M. Y., Hadjistavropoulos, H. D., \& Katapally, T. R. (2020). The complex association of barriers and interest in internet-delivered cognitive behavior therapy for depression and anxiety: Informing e-health policies through exploratory path analysis. Journal of Mental Health (Abingdon, England). https://doi.org/10. 1080/09638237.2020.1793125

National Association of Social Workers. (2017). Code of ethics. Retrieved from https://www.socialworkers.org/About/Ethics/ Code-of-Ethics/Code-of-Ethics-English

Neff, K. D., \& Germer, C. K. (2013). A pilot study and randomized controlled trial of the mindful self-compassion program. Journal of Clinical Psychology, 69, 28-44.

Nhat Hanh, T. (1998). The heart of the Buddha's teaching: Transforming suffering into peace, joy, and liberation. Parallax.

Niles, B. L., Vujanovic, A. A., Silberbogen, A. K., Seligowski, A. V., \& Potter, C. M. (2013). Changes in mindfulness following a mindfulness telehealth intervention. Mindfulness, 4, 301-310.

Ortner, C. N., Kilner, S. J., \& Zelazo, P. D. (2007). Mindfulness meditation and reduced emotional interference on a cognitive task. Motivation and Emotion, 31, 271-283.

Panchal, N., Kamal, R., Orgera, K., Cox, C., Garfield, R., Hamel, L., Munana, C., \& Chidambaram, P. (2020). The implications of COVID-19 for mental health and substance use. Issue Brief. Retrieved from https://abtcounseling.com/wp-content/uploads/ 2020/09/The-Implications-of-COVID-19-for-Mental-Health-andSubstance-Use-_-KFF.pdf

Pew Research Center. (2021). Internet \& Technology. Retrieved from https://www.pewresearch.org/internet/fact-sheet/mobile/

Pruitt, I. T., \& McCollum, E. E. (2010). Voices of experienced meditators: The impact of meditation practice on intimate relationships. Contemporary Family Therapy, 32, 135-154.

Reay, R. E., Looi, J. C. L., \& Keightley, P. (2020). Telehealth mental health services during COVID-19: Summary of evidence and clinical practice. Australasian Psychiatry, 28, 514-516. https:// doi.org/10.1177/1039856220943032

Rothaupt, J. W., \& Morgan, M. M. (2007). Counselors' and counselor educators' practices of mindfulness: A qualitative inquiry. Counseling and Values, 52, 40-54.

Saurman, E., Kirby, S. E., \& Lyle, D. (2015). No longer "flying blind": How access has changed emergency mental health care in rural and remote emergency departments, a qualitative study. $B M C$ Health Services Research, 15(1), 1-11. https://doi.org/10.1186/ s12913-015-0839-7

Sher, L. (2020). The impact of the COVID-19 pandemic on suicide rates. QJM: International Journal of Medicine, 113, 707-712. https://doi.org/10.1093/qjmed/hcaa202

Shoham, A., Hadash, Y., \& Bernstein, A. (2018). Examining the decoupling model of equanimity in mindfulness training: An intensive experience sampling study. Clinical Psychological Science, 6(5), 704-720. https://doi.org/10.1177/2167702618770446 
Tomlinson, E. R., Yousaf, O., Vitterso, A. D., \& Jones, L. (2018). Dispositional mindfulness and psychological health: A systematic review. Mindfulness, 9, 23-43. https://doi.org/10.1007/ s12671-017-0762-6

Tran, V. (2013) Positive Affect Negative Affect Scale (PANAS). In M. D. Gellman, \& J. R. Turner (Eds.), Encyclopedia of behavioral medicine. Springer. https://doi.org/10.1007/978-1-4419-1005-9_ 978

Tuong, W., Larsen, E. R., \& Armstrong, A. W. (2014). Videos to influence: A systematic review of effectiveness of video-based education in modifying health behaviors. Journal of Behavioral Medicine, 37, 218-233.

Wahbeh, H., Svalina, M. N., \& Oken, B. S. (2014). Group, one-onone, or internet? Preferences for mindfulness meditation delivery format and their predictors. Open Medicine Journal, 1, 66-74.

Watson, D., Clark, L. A., \& Tellegen, A. (1988). Development and validation of brief measures of positive and negative affect: the PANAS scales. Journal of Personality and Social Psychology, 54(6), 1063-1070.
Williston, S. K., Martinez, J. H., \& Abdullah, T. (2019). Mental health stigma among people of color: An examination of the impact of racial discrimination. International Journal of Social Psychiatry, 65, 458-467. https://doi.org/10.1177/0020764019858651

Zeidan, F., Johnson, S. K., Diamond, B. J., David, Z., \& Goolkasian, P. (2010). Mindfulness meditation improves cognition: Evidence of brief mental training. Consciousness and Cognition, 19, 597-605.

Publisher's Note Springer Nature remains neutral with regard to jurisdictional claims in published maps and institutional affiliations.

Adam W. Hanley is an Assistant Professor at the Center on Mindfulness and Integrative Health Intervention Development (C-MIIND) in the University of Utah College of Social Work. The goal of his research program is to optimize the delivery of mindfulness-based interventions. 